\title{
Developing a new approach for the anticipation of subsurface pressure in three oil wells from various fields in Iraq
}

\author{
Rafid K. Abbas ${ }^{1}$ (D)
}

Received: 27 September 2021 / Accepted: 21 October 2021 / Published online: 11 November 2021

(c) The Author(s) 2021

\begin{abstract}
Subsurface pressure quantification is the main goal for all drilling engineers due to its vital importance to minimizing drilling costs and preventing various excavating dilemmas such as stuck pipe, pipe collapsing, lost circulation, and well kick. Formation pressure is measured directly in producing hydrocarbon zones using special equipment; however, it is difficult to obtain pore pressure measurements in other intervals; therefore, many approaches were suggested and developed to anticipate the geopressure due to its importance on the drilling operation. Traditionally, Eaton's method is the most widely used for geopressure anticipation from well logs. In the current study, a new proposed formula for geopressure determination was derived from the modified Eaton's equation which is based on the inception of the mechanical specific energy. The study was applied on three oil-producing wells from different fields in Iraq (Missan C, West Qurna 15, and Zubair 171). The estimated subsurface pressure from the new suggested approach was validated by comparison with the actual in situ subsurface pressure obtained from Drill Stem Test (DST) and Repeated Formation Test (RFT). Statistical analysis is used for the validation by applying Mean squared error (MSE) and Mean Absolute percentage Error (MAE). Encouraging results were obtained from the present research for all wells being studied. The main finding of the current work is involving a new parameter (mechanical specific energy) for subsurface pressure determination, where it was not included in the previous techniques of geopressure equations. It was found that the value of exponent $(m)$ in the new proposed equation has a significant influence on the predicted geopressure, where $(m)$ varies from 0.1626 to 0.6896 depending on the type of the excavated rock plus the materials that the drill bit is manufactured of, where the interaction between these components is vital. The present work could be a useful method when planning to excavate a new well adjacent to the area of the investigated wells, where special well logs are unavailable for pore pressure measurement and suitable usage of mud weight is highly needed for the overall drilling process.
\end{abstract}

Keywords Geopressure $\cdot$ Subsurface pressure $\cdot$ Missan $\cdot$ Zubair $\cdot$ Specific energy

\section{Nomenclature}

DST Drill Stem Test

$d_{c n} \quad$ Dc exponent values derived from the normal trend line (dimensionless)

$d_{c o} \quad$ Observed $d c$ exponent values (dimensionless)

Gnp Hydrostatic or normal pressure gradient (psi/ft)

Gob Overburden pressure gradient (psi/ft)

Gpp Geopressure pressure gradient (psi/ft)

$H_{a} \quad$ Hardness of the bit $\left(\mathrm{N} / \mathrm{m}^{2}\right)$

$H_{W} \quad$ Hardness of the rock being spudded $\left(\mathrm{N} / \mathrm{m}^{2}\right)$

MAE Mean Absolute Error (fraction or percentage)

Rafid K. Abbas

Rafid.Abbas@qu.edu.iq

1 Chemical Engineering Department, Faculty of Engineering, University of Al-Qadisiyah, Al-Diwaniya 58002, Iraq

\begin{tabular}{|c|c|}
\hline MSE & Mean Squared Error \\
\hline MWD & Measurements While Drilling logs \\
\hline$m$ & $\begin{array}{l}\text { Exponent in Eaton's modified formula } \\
\text { (dimensionless) }\end{array}$ \\
\hline$N$ & Number of readings \\
\hline NL & Normal compaction trend line \\
\hline PDC & Poly diamond crystalline bits \\
\hline RFT & Real formation test \\
\hline$R_{n}$ & $\begin{array}{l}\text { Resistivity derived from the normal compaction } \\
\text { line (ohm.m) }\end{array}$ \\
\hline$R_{o}$ & Observed or measured resistivity (ohm.m) \\
\hline$M S$ & Specific energy (psi) \\
\hline$M S_{n}$ & Normal specific energy (psi) \\
\hline$M S_{o}^{n}$ & Observed specific energy (psi) \\
\hline$V(I)_{a}$ & Actual values of a parameter \\
\hline$V(I)_{c}$ & Calculated values for a parameter \\
\hline
\end{tabular}


$\Delta t_{n} \quad$ Acoustic time at the normal compaction line ( $\mu$ sec./ft)

$\Delta t_{o} \quad$ Observed acoustic time ( $\mu$ sec./ft)

\section{Introduction}

Subsurface pressure estimation is significant for both exploration and drilling projects. Optimizing well planning and drilling decisions in overpressure zones, where the geopressure is greater than the normal pressure (hydrostatic), is crucial to perform geopressure forecasts before drilling. Mud weight is the vital element to control the well stability depending on the pore pressure situation to prevent numerous drilling problems such as blowout, lost circulation, well kick, and reservoir destruction, which consequently leads to reducing the cost and an economic drilling, would be achieved.

Traditionally, there are various approaches to speculate subsurface pressure, especially from well logs that mainly depend on seismic velocity data. The well-known Eaton's method commonly used for the geopressure speculation from sonic travel time data as well as from resistivity logs. Eaton's formula may produce an error if the normal compaction trend line used for determining the normal hydrostatic pressure is not precisely drawn and accordingly corrections should take place (Chatterjee et al. 2012). Simulation approaches that depend on the seismic log data were carried out to obtain a reliable model for pore pressure determination where an encouraging results were obtained (Asedegbega et al. 2021). A recent study was performed for the goal of pore pressure determination using Artificial Neural Network (ANN) where this technique was successfully applied previously for the estimation of rate of penetration where reasonable results were produced (Markovic et al. 2021). Simulation approaches encourage further investigation for geopressure estimation as a successful alternative of actual pore pressure measurement. A recent study of using nanoparticles in drilling shows that the combination of nanoparticles and smart fluids could create a highly efficient sensor that can operate properly in extremely difficult drilling conditions and can provide precise measurements of temperature, geopressure, oil flow rate and tension in deep wells (Lastname 2018). Special nanoparticles (NPs) were added to the drilling mud can cause a drop in permeability and abnormal pressure. This novel finding could help dramatically the reduction in overpressure in the areas that suffer from the dilemma of high subsurface pressure (Saleh and Ibrahim 2019).

Abnormal formation pressure is one of the main drilling problems that should be dealt seriously to prevent the destruction consequences might be occurred; therefore, instantaneous monitoring of the pore pressure is indispensable along the excavation of any well. Many researches in the literature dealt with this issue (Fertl and Timko 1971; Holm 1998; Swarbrick et al. 1998). However, few researches were carried out on determining the subsurface pressure from the inception of Mechanical Specific Energy (MS), where the final obtained geopressure formula was applied on selected wells in Nigeria where good results were produced (Oloruntobi et al. 2018; Oloruntobi and Butt 2019).

All previous approaches available in the literature were targeting the determination of geopressure with fewer errors due to its crucial significance on overall drilling operation.

The main target of the current study is to suggest a new formula of subsurface pressure gradient that involves the main parameters of the penetrated rock along with the parameters of the drill bit itself, where there is shortage of covering this combination in the available literature.

\section{Area of study}

Three oil-producing wells were investigated in the current study, where the data were brought from geological reports, bit records, and well logs. The in situ actual geopressure was collected by the benefit of Repeated Formation Test (RFT) and Drill Stem Test (DST). The wells being investigated in the present research are Missan C, Zubair 171 and West Qurna 15 in south of Iraq.

Missan oil fields lie about $175 \mathrm{~km}$ north of Basrah province southern Iraq near to the border with Iran. Missan fields consist of Buzurgan, Abu Ghirab and Jabal Fauqi (Fakka) oil fields. The production of these fields reached $450.000 \mathrm{barrel} /$ day, and the reserves is proved to be 2.5 billion barrels of oil. MS-C well was chosen to be involved the current study.

The second well included in the present study is Zubair-171 in Zubair supergiant oil field, which considered one of the largest hydrocarbon fields in the world. This field is located around $20 \mathrm{~km}$ west of Basrah city south of Iraq.

The last well being investigated in the current research is West Qurna-15 in West Qurna giant oil field that lies in north of Rumaila oil field, west of Basrah. West Qurna is believed to have a reserve of around 43 billion barrels.

Figure 1 illustrates the location of three selected oil fields in southern Iraq that involves the three wells under study. The three studied wells are located in different geographical locations; consequently, various geological aspects are featured with each one, especially the stratigraphic columns.

\section{Theoretical background and methodology}

Formation pressure is predicted using several approaches mainly from Logging While Drilling (LWD), such as porosity, resistivity and sonic $\operatorname{logs}$ as well as where empirical formulas were obtained (Zhang 2011). The accuracy of these 


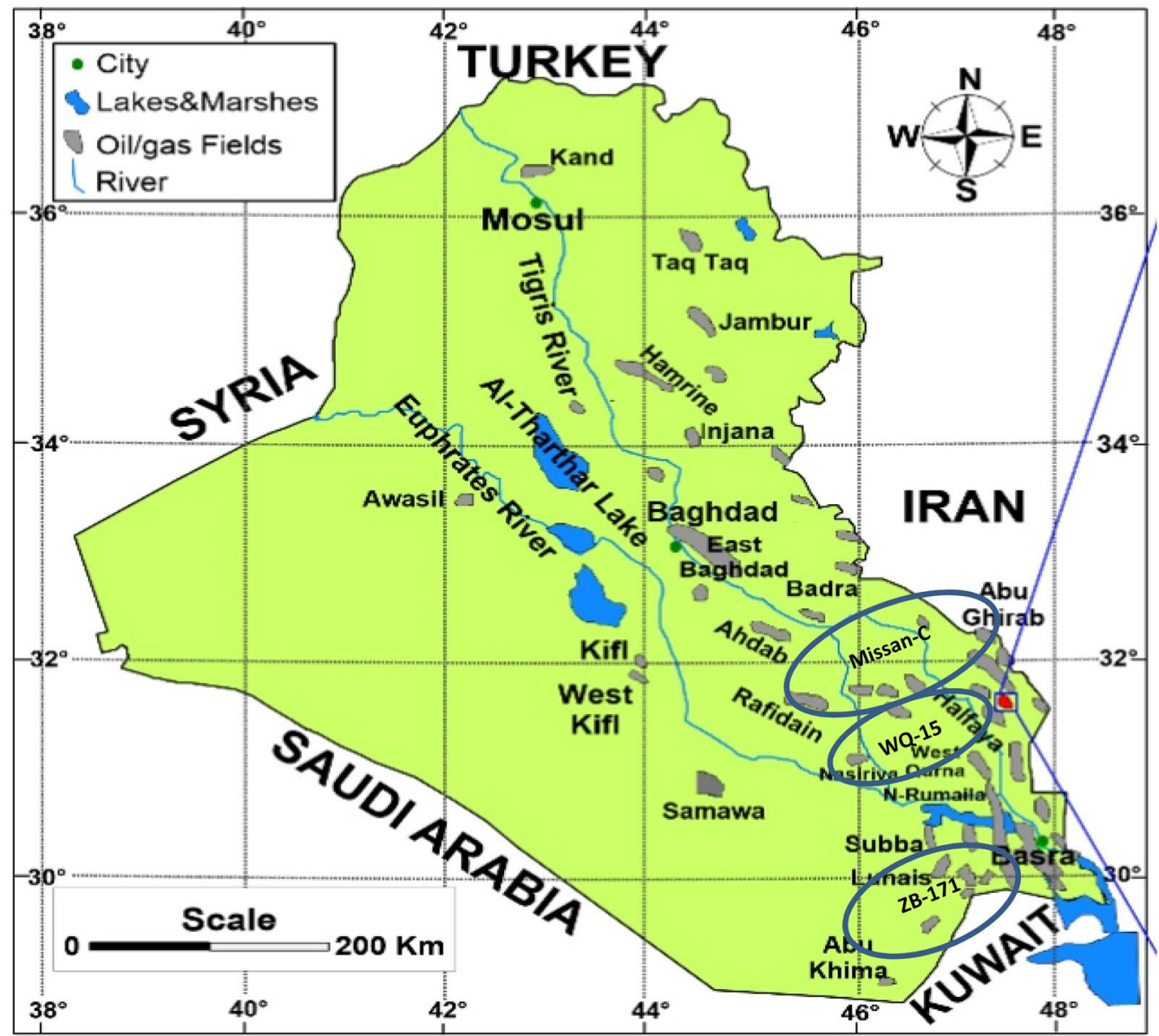

Fig. 1 Map or Iraq demonstrating the location of the particular oil wells being investigated (Abbas et al. 2020)

techniques was encouraging and consequently used for other calculations in well design. Other methods depend on seismic data for the forecasting of formation pressure based on (velocity and acoustic impedance), where also some empirical equations were developed with acceptable results were obtained (Pennebaker 1968). Drilling parameters could also be used for the speculation of pore pressure. The d-exponent approach was the oldest empirical formula for predicting the geopressure from drilling parameters (Rehm and Mcclendon 1971). Depending on just one approach could lead to misinterpretations; therefore, it is preferable to monitor the combination of the available data for instance, in cases of well caving, well logs might produce imprecise results, whereas drilling parameters might lead to better results. Furthermore, under severe bit conditions, well logs could provide more precise pore pressure estimation than the geopressure from drilling parameters. In the literature, the traditional Eaton formulas are implemented for the prediction of pore pressure from drilling parameters, i.e., dc exponent and from well logs (transit time and resistivity) as shown in Eqs. 1-3 as follows (Eaton 1975):
$G p p=G o b-\{G o b-G n p\} *\left[\frac{d c o}{d c n}\right]^{1.2}$

$G p p=G o b-\{G o b-G n p\} *\left[\frac{\Delta t n}{\Delta t o}\right]^{3}$

$G p p=G o b-\{G o b-G n p\} *\left[\frac{R o}{R n}\right]^{1.2}$

where ( $d c o$ ) is the observed $d c$ values (unitless), $(d c n)$ is the $(d c)$ values taken from the normal compaction trend line (dimensionless), $(\Delta t n)$ is the transit time at the normal compaction trend line $(\mu \mathrm{sec} . / \mathrm{ft}),(\Delta t o)$ is the observed transit time ( $\mu$ sec./ft), $(R o)$ is the measured resistivity (ohm.m), $(R n)$ is the resistivity taken from the normal trend line, $(G p p)$ is the geopressure gradient (psi/ft), $(G o b)$ is the overburden pressure gradient (psi/ft), and (Gnp) is the normal or hydrostatic pressure gradient (psi/ft).

Determination of geopressure can be carried out by using the inception of mechanical specific energy $(M S)$ 
based on the rule that overpressure intervals that possess low effective stress need less energy to excavate the rock formation rather than the intervals that have normal or hydrostatic pressure at the same depth according to the definition of the specific energy presented in Eq. (4a).

Specific energy $=\frac{\text { Energy rate }}{\text { Volume rate of the rock being exavated }}$

Oloruntobi et al. (2018), Oloruntobi and Butt (2019) suggested a new method to quantify the geopressure. The proposed new model was derived from the rotary and hydraulic energies. The new approach is based on the hydraulic specific energy which is the combination of axial, hydraulic and torsional energies (Oloruntobi et al. 2018; Oloruntobi and Butt 2019). However, the previous approaches obtained encouraging results and improvement should be done to include the effect of the rock formation hardness as well as the hardness of the drill bit. No references in the literature include this significant effect; therefore, an essential development of Eaton's formula was carried out.

$$
\begin{aligned}
H M S= & \frac{\text { Axial Energy }}{\text { Rock Volume Excavated }}+\frac{\text { Hydraulic Energy }}{\text { Rock Volume Drilled }} \\
& +\frac{\text { Torosional Energy }}{\text { Rock Volume being drilled }}
\end{aligned}
$$$$
H M S=\frac{W O B}{A_{b}}+\frac{1154 * \Delta p_{b}}{A_{b} * R O P}+\frac{120 * \pi * N * T}{A_{b} * R O P}
$$

where $W O B$ is the weight on bit (lb), $\mathrm{d}$ is the bit diameter (in), $N$ is the bit rotary speed (rpm), $R O P$ is the penetration rate (ft/hr), $T$ is the bit torque (ib.ft), $A_{b}$ is the surface area of the bit $\left(\mathrm{in}^{2}\right), \Delta p_{\mathrm{b}}$ is the pressure drop at the bit (psi), and $H M S$ is expressed in psi.

Quantification of geopressure gradient at any certain depth could be determined by modifying one of Eaton's equation sets (1-3) and replacing the hydraulic specific energy instead of the other parameters. The new proposed formula of geopressure gradient is presented in Eq. (6).

$G p p=G o b-\{G o b-G n p\} *\left[\frac{H M S_{o}}{H M S_{n}}\right]^{m}$

where $H M S_{o}$ represents the observed hydraulic mechanical specific energy (psi), $H M S_{\mathrm{n}}$ denotes the normal hydraulic mechanical specific energy, and $(m)$ is the power that should be known. The power in Eq. (6) $(m)$ varies from a specific region to another.

By the beneficial of Eq. (7), Abbas (2017) suggested a new formula for the determination of the mechanical specific energy instead of using Eq. (5), because in many cases the bit torque is not unavailable (Abbas 2017). The proposed formula in Eq. (7) is based on the drilling properties as well as the mechanical effects on the specific energy, especially the hardness of the rock and materials that form the drill bit. After a series of derivations shown in Appendix A, the new suggested formula of mechanical specific energy is as follows:

$M S=\frac{K_{1} H_{W}}{\left(\frac{H_{a}}{H_{W}}\right)^{2.5}}$

where $M S$ is the mechanical specific energy (psi), $H_{W}$ is the hardness of the rock formation being excavated $(\mathrm{N} /$ $\left.\mathrm{m}^{2}\right), H a$ is the hardness of the materials forming the bit $(\mathrm{N} /$ $\mathrm{m}^{2}$ ), and $K_{1}$ is a constant for the conversion which equals to $(28,137.862)$.

Substituting Eq. (7) into Eq. (6) leads to the following:

$G p p=G o b-\{G o b-G n p\} *\left[\frac{M S_{o}}{M S_{n}}\right]^{m}$

The power $(m)$ in Eq. (8) can be determined by the following simplification steps:

Taking Logarithm of both sides of Eq. (8) yields the following:

$\log (G o b-G p p)=\log [G o b-G n p]+m \log \left[\frac{M S o}{M S n}\right]$

$\log \left[\frac{G o b-G p p}{G o b-G n p}\right]=m \cdot \log \left[\frac{M S o}{M S n}\right]$

Sketching $\log \left[\frac{G o b-G p p}{G o b-G n p}\right]$ vs. $\log \left[\frac{M S o}{M S n}\right]$, the exponent $(m)$ which represents the slope could be determined accordingly.

In the present research, the following procedure is followed to quantify the geopressure gradient as shown below:

1. By the benefit of bit record, all drill bits been used have commercial numbers that need to be identify their type (Tri-cone rotary, Insert or PDC bits). Bit classification charts are used for the purpose of determining the type of drill bit which corresponds to the commercial bit type. If the type of the drill bit is known, the hardness of the drill bit tooth will be known accordingly (IADC classification chart 2008).

2. From the geological reports as well as from the study of Almahdawi (2016) (Abbas 2017), the lithology of Missan oil field is prepared to extract the hardness value of the rock layer being drilled in the current study as shown in Fig. 2, whereas the lithologies for the other two wells were gathered from the geological reports relevant of the two wells. The hardness of the materials forming the bit according to its type is collected from Table 1 (Mouritz and Hutchings 1991; Gokhale 2010). 
3. From the literature, the hardness of the roller tungsten carbide (TC) bit is $15 \mathrm{GPa}$, whereas the hardness of the roller milled bit is approximately $12.95 \mathrm{GPa}$ (IADC classification chart 2008; Osipov et al. 2010); therefore, the values of the hardness of the bits are determined.

4. The observed mechanical specific energy values $\left(M S_{o}\right)$ from Eq. (7) are computed. Next, the $(M S)$ values vs. depth are plotted.

5. The Mechanical Specific Energy $(M S)$ vs. depth is sketched, where the values of the observed $(M S)$ that lie in a normal increasing trend represent the normal compaction trend line that means the normal or hydrostatic geopressure zone. Any inclination from this normal trend line denotes abnormal pressure regions.

6. Plotting $\log \left[\frac{G o b-G p p}{G o b-G n p}\right]$ vs. $\log \left[\frac{S E O}{S E n}\right]$, in order to find the value of the exponent $(m)$. The value of $(m)$ is the most significant parameter that should be obtained in order to quantify the subsurface pressure gradient. It is worth mentioning that the value of $(m)$ may differ from one area to another relying on several effective parameters.

7. After knowing the value of the exponent $(\mathrm{m})$, the geopressure gradient can be computed by implementing
Table 1 Type of rock formations being drilled in the current work with their corresponding values of hardness [19.20]

\begin{tabular}{lc}
\hline Rock type & Hardness $(\mathrm{GPa})$ \\
\hline Sandstone & 10.79 \\
Limestone & 1.079 \\
Dolomite & 2.45 \\
Shale & 1.961 \\
Anhydrite & 1.569 \\
Conglomerate & 1.17 \\
\hline
\end{tabular}

Eq. (8). It is worthy to mention that the normal trend line of the pore pressure gradient should be created, where at high pressure intervals, the geopressure gradient rises from the hydrostatic or normal pressure gradient trend line with depth. It is crucially important to collect the information obtained from steps $1-6$, as each step hence depends on the previous one; therefore, the quantification of the geopressure gradient from the current approach would not be useful if any step above was not performed successfully.

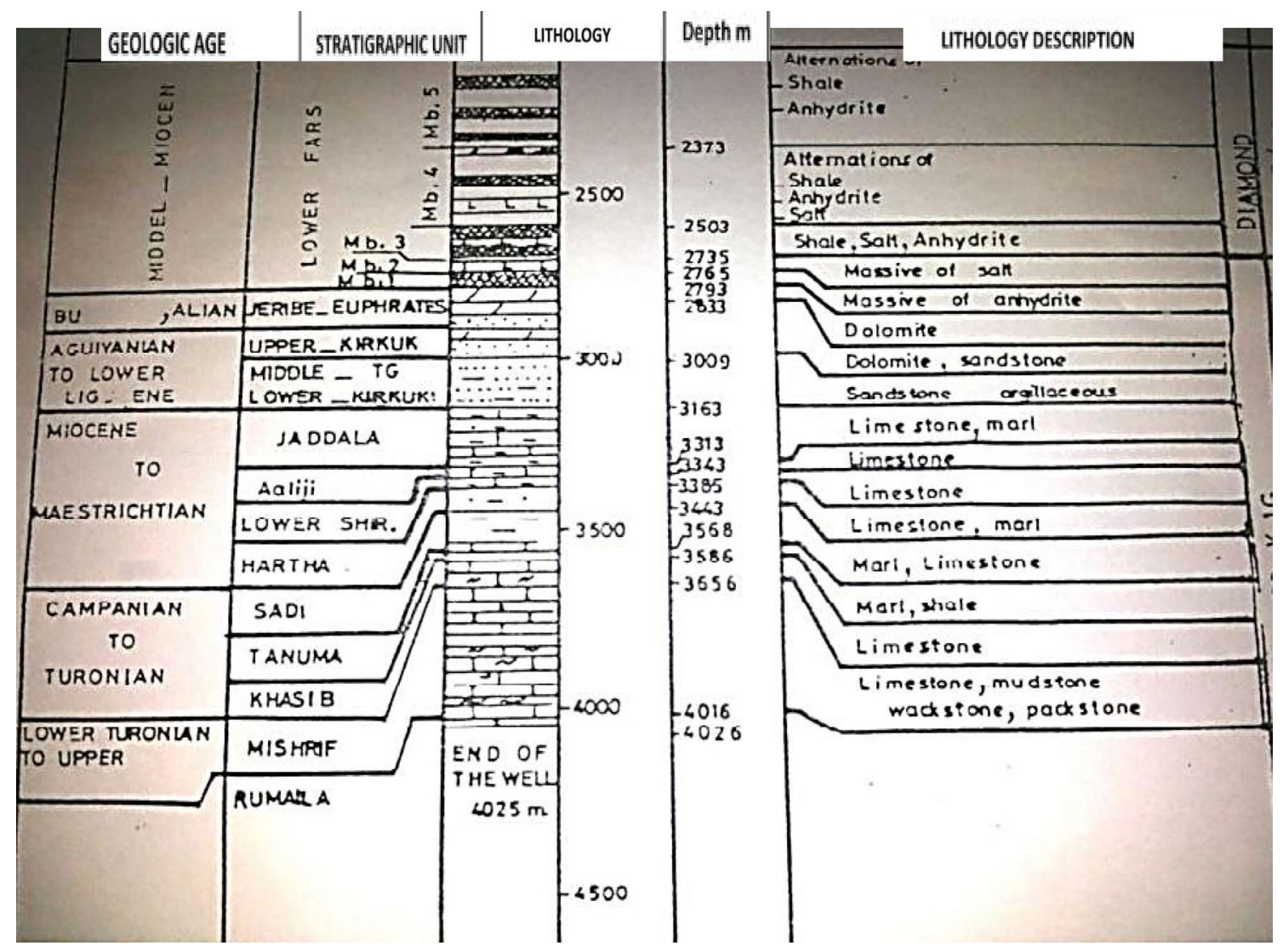

Fig. 2 Stratigraphic column of Missan oil field southern Iraq showing the rock formation being penetrated in the current study with depth (Almahdawi 2016) 
8. Then, the speculated values of the subsurface gradient with the in situ actual geopressure gradient are validated. A comparative study between the anticipated and the actual geopressure gradient is carried out to validate the proximity of each well with the actual subsurface pressure gradient. A statistical formula can be applied to enhance the validation. Statistical Mean Absolute Error $(M A E)$ is used for this purpose. Furthermore, another statistical formula is used, i.e., Mean Squared Error $(M S E)$ as follows:

$$
\begin{aligned}
& M A E=\left[\frac{1}{N} \sum_{i=1}^{N}\left|\frac{V(I)_{a}-V(I)_{c}}{V(I)_{a}}\right|\right] \\
& M S E=\left[\frac{1}{N} \sum_{i=1}^{N}\left(V(I)_{a}-V(I)_{c}\right)^{2}\right]
\end{aligned}
$$

where $M A E$ is in (percentage or fraction), $V(I)_{a}$ is the measured or (actual) values of a parameter, $V(I)_{c}$ is the computed (predicted) values for the same parameter, and $N$ is the readings number for a sample. Thus, $M A E$ is a useful indicator for the comparison between the actual values for any model with the predicted ones. The model that has the lowest value of $M A E$ is the closest to the actual. MSE is also a good indicator for the validation between the predicted and the observed values. When MSE is close to zero, it means that the model is the closest to the observed values. (Huber 1964). Therefore, the two aforementioned statistical tests shown in Eqs. 9 and 10 were used to validate the anticipated geopressure gradient with the actual in-situ one.

It is concluded that the proposed formula of the mechanical specific energy depends mainly on the mechanical properties of the rock and the drill bit used to penetrate it. Furthermore, the suggested equation of geopressure relies mainly on the exponent $(m)$ in Eq. (8) which affects vitally the intensity of the speculated subsurface pressure.

\section{Results and discussion}

The necessary data for completing the rest of calculations, aforementioned in the procedure steps above, are shown in Table 2 for well Missan C. The data were collected from geological and bit record reports and well logs for three hydrocarbon wells in southern Iraq: (Missan C, Zubair 171 and West Qurna 15). It should be noted that the in situ or actual pore pressure gradient is provided from Repeated Formation Test (RFT) and Drill Stem Test (DST).

The mechanical specific energy $(M S)$ is determined from Eq. (7) and tabulated in Table 3 for well Missan C, where $(M S)$ clearly relies mainly on the hardness of the rock and the drill bit that excavates the rock formations. Values of $(M S)$ are plotted vs. depth, where the normal trend line (NL) should be established as demonstrated in Fig. 3. The normal trend line denotes the values of normal (hydrostatic) pressure. It is worthy to mention that, the mechanical specific energy at the normal compaction trend line denotes the normal mechanical specific energy $(\mathrm{MSn})$ at hydrostatic or normal geopressure, where any inclination from the normal trend line represents regions of either surpressure or overpressure. Figure 3 shows how the mechanical specific energy $(M S)$ increases gradually with depth for well \# Missan C which represents the normal pore pressure zones until reaching depth $(2020 \mathrm{~m})$, where $(M S)$ started to decrease sharply till the end of the well detecting an overpressure region as illustrated in Fig. 3a.

For well West Qurna 15, the mechanical specific energy increases slightly with depth until depth $(3300 \mathrm{~m})$ representing hydrostatic pressure region. Afterward, a sever reduction of $(M S)$ values was observed clearly. This reduction illustrates the detection of three high overpressure zones, i.e. (3300-3910 m), (3910-4115 m) and $(4115-4550 \mathrm{~m})$ as illustrated in Fig. 3b. This abnormal pressure is attributed mainly to the existence of anhydrite and salt series that extends from Sulaiy to Najmah formations.

The behavior of specific energy for well Zubair 171 is quite different from the previous two wells as shown in Fig. 3c. The $(M S)$ values rise normally with depth exhibiting normal pore pressure zone until depth $(1938 \mathrm{~m})$ where $(M S)$ values dropped until depth $(2088 \mathrm{~m})$ encountering a slight overpressure zone. Afterward, $(M S)$ shows a dramatic rise until depth $(2280 \mathrm{~m})$ denoting a slight surpressure (below hydrostatic pressure). The values of $(M S)$ after depth $(2280 \mathrm{~m})$ exhibiting a sharp reduction until reaching depth $(2330 \mathrm{~m})$ demonstrating the recovery of the subsurface pressure to its normal trend.

Next step is the surveillance of the anticipated geopressure with depth. For this purpose, the value of the power $(m)$ in Eq. (8) should be determined in order to quantify the subsurface pressure gradient. Therefore, a sketch of $\log \left[\frac{G o b-G p p}{G o b-G n p}\right]$ vs. $\log \left[\frac{S E O}{S E n}\right]$ must be achieved. Figure 4 exhibits the determination of the power $(m)$ in Eq. (8) for wells Missan C, West Qurna 15, and Zubair 171).

From Fig. 4, it is shown that the power (m) for wells Missan C, West Qurna, and Zubiar 171were (0.6896), (0.5617), and (0.1626), respectively. Surprisingly, the values of the slope $(\mathrm{m})$ are increased in the upward direction as the well Zubair 171 located at the south of the rest two investigated wells and the well Missan C is lied on the north of the rest two wells. Figure 1 shows the geographical locations of the three wells. 
Table 2 Sample of the data derived from well logs, geological reports, and bit records for well Missan C in south of Iraq showing the main parameters of the drill bit and the rock being penetrated

\begin{tabular}{|c|c|c|c|c|c|c|c|}
\hline Depth (m) & $\begin{array}{l}\text { Overburden pressure } \\
\text { gradient, Gob (psi/ft) }\end{array}$ & $\begin{array}{l}\text { In situ geo pressure } \\
\text { gradient, Gpp (psi/ } \\
\text { ft) }\end{array}$ & $\begin{array}{l}\text { Bit com- } \\
\text { mercial } \\
\text { name }\end{array}$ & Bit type & $\begin{array}{l}\text { Hardness } \\
\text { of bit, Ha } \\
\text { (Gpa) }\end{array}$ & Formation name & Rock formation type \\
\hline 637 & 0.92352 & 0.49244 & JD4 & Milled-tooth & 12.95 & Injana (Upper Faris) & $\begin{array}{l}\text { Calcareous clay with } \\
\text { sand gravel and } \\
\text { siltstone }\end{array}$ \\
\hline 897 & 0.93132 & 0.50024 & JD4 & Milled-tooth & 12.95 & Injana (Upper Faris) & $\begin{array}{l}\text { Calcareous clay with } \\
\text { sand gravel and } \\
\text { siltstone }\end{array}$ \\
\hline 989 & 0.93912 & 0.494 & JD4 & Milled-tooth & 12.95 & Injana (Upper Faris) & $\begin{array}{l}\text { Calcareous clay with } \\
\text { sand gravel and } \\
\text { siltstone }\end{array}$ \\
\hline 1132 & 0.94536 & 0.4862 & S33 & Milled-tooth & 12.95 & Injana (Upper Faris) & $\begin{array}{l}\text { Calcareous clay with } \\
\text { sand gravel and } \\
\text { siltstone }\end{array}$ \\
\hline 1258 & 0.95264 & 0.4992 & S33 & Milled-tooth & 12.95 & Injana (Upper Faris) & $\begin{array}{l}\text { Calcareous clay with } \\
\text { sand gravel and } \\
\text { siltstone }\end{array}$ \\
\hline 1300 & 0.9542 & 0.48932 & JD4 & Milled-tooth & 12.95 & Injana (Upper Faris) & $\begin{array}{l}\text { Calcareous clay with } \\
\text { sand gravel and } \\
\text { siltstone with traces } \\
\text { of Anhydrite }\end{array}$ \\
\hline 1515 & 0.9698 & 0.48984 & FS5 KJ & Milled-tooth & 12.95 & Injana (Upper Faris) & $\begin{array}{l}\text { Calcareous clay with } \\
\text { sand gravel and } \\
\text { siltstone with traces } \\
\text { of Anhydrite }\end{array}$ \\
\hline 1643 & 0.97708 & 0.48152 & FS5 KJ & Milled-tooth & 12.95 & Injana (Upper Faris) & $\begin{array}{l}\text { Calcareous clay with } \\
\text { sand gravel and } \\
\text { siltstone with traces } \\
\text { of anhydrite }\end{array}$ \\
\hline 1903 & 0.99424 & 0.50648 & LMG & Milled-tooth & 12.95 & Injana (Upper Faris) & $\begin{array}{l}\text { Clay, gravel, traces } \\
\text { of gypsum, traces } \\
\text { of sandstone and } \\
\text { anhydrite }\end{array}$ \\
\hline 2016 & 0.99892 & 0.49244 & J33 & Milled-tooth & 12.95 & Injana (Upper Faris) & $\begin{array}{l}\text { Clay, gravel, traces } \\
\text { of gypsum, traces } \\
\text { of sandstone and } \\
\text { anhydrite }\end{array}$ \\
\hline 2112 & 1.00152 & 0.5642 & $\mathrm{~J} 33$ & Milled-tooth & 12.95 & $\begin{array}{l}\text { Fatha (Lower Faris) } \\
\text { mb5 }\end{array}$ & $\begin{array}{l}\text { Alternations of shale } \\
\text { and anhydrite }\end{array}$ \\
\hline
\end{tabular}

Table 3 Sample of the calculated values of the mechanical specific energy from Eq. (7), in situ actual and predicted geopressure for well Missan C, south of Iraq

\begin{tabular}{lllll}
\hline Depth (m) & $\begin{array}{l}\text { Observed specific } \\
\text { energy (MSo), Mpsi }\end{array}$ & $\begin{array}{l}\text { Normal specific } \\
\text { energy }(M S n), \text { Mpsi }\end{array}$ & $\begin{array}{l}\text { In-situ geopressure } \\
\text { gradient, Gpp (psi/ft) }\end{array}$ & $\begin{array}{l}\text { Forecasted geopressure } \\
\text { gradient, Gpp (psi/ft) }\end{array}$ \\
\hline 637 & 89,291 & 89,275 & 0.492 & 0.492 \\
897 & 95,133 & 95,072 & 0.500 & 0.500 \\
989 & 96,773 & 96,811 & 0.494 & 0.494 \\
1132 & 100,112 & 98,840 & 0.486 & 0.486 \\
1258 & 102,098 & 101,793 & 0.499 & 0.499 \\
1300 & 103,245 & 102,898 & 0.489 & 0.489 \\
1515 & 104,112 & 103,673 & 0.490 & 0.490 \\
1643 & 108,820 & 109,275 & 0.482 & 0.482 \\
1903 & 107,037 & 114,200 & 0.506 & 0.506 \\
2016 & 116,166 & 116,521 & 0.492 & 0.492 \\
2112 & 70,194 & 118,260 & 0.564 & 0.564 \\
\hline
\end{tabular}



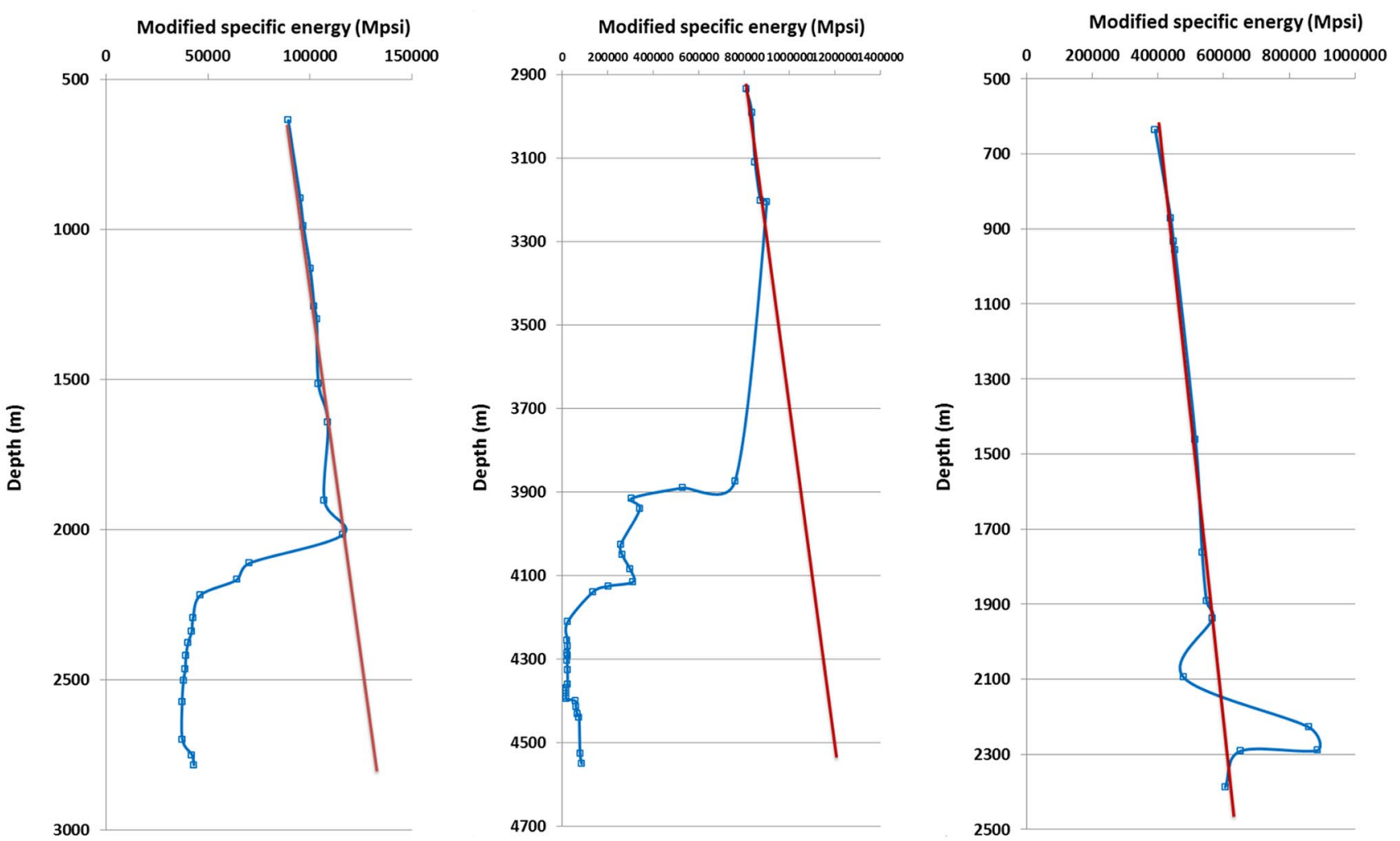

Fig. 3 Plot of the calculated mechanical specific energy vs. depth for three wells southern Iraq (a Missan C, b West Qurna 15, and c Zubair 171)

The most significant step now is to determine the subsurface pressure gradient from the suggested formula, i.e. Equation (8). The computations of the predicted formation pressure gradient is tabulated in the last column of Table 3 for well Missan C. The anticipated pore pressure gradient from the proposed formula along with the in situ (actual) geopressure gradient taken from well logs, DST, and RFT is plotted vs. depth for the three wells as illustrated in Fig. 5. The plot shows the rapprochement between the forecasted and the actual geopressure gradient.

Figure 5 demonstrates the behavior of the anticipated geopressure gradient along with the in situ or actual subsurface pressure gradient where good rapprochement was noticed.

For well Missan C, the forecasted formation pressure exhibits a normal geopressure gradient from the beginning until nearly depth $(2020 \mathrm{~m})$, where the subsurface pressure gradient started to elevate dramatically showing an overpressure zone which extends till the end of the well as shown in Fig. 5a. The value of the pore pressure gradient at this overpressure zone ranged $(0.51-0.781 \mathrm{psi} / \mathrm{ft})$. The existence of overpressure in the wells of Missan field is most probably attributed to the multiple cap rocks originated from the beds uncompacted shale interceded with anhydrite, dolomite and salt beds. Salt rocks behave as seals for entrapment of salt water causing abnormal pressure (Al-Rubaiee 1987).
For well West Qurna 15, the abnormal formation pressure gradient encountered at three intervals (3300-3910 m), (3910- $4115 \mathrm{~m})$ and $(4115-4550 \mathrm{~m})$ showing geopressure gradients $(0.5-0.752 \mathrm{psi} / \mathrm{ft}),(0.752-0.789 \mathrm{psi} / \mathrm{ft})$, and (0.789-0.99 psift) which is approximately compatible with the actual geopressure gradient as illustrated in Fig. 5b. The predicted pore pressure gradient declined slightly from the highest abnormal to about $(0.92 \mathrm{psi} / \mathrm{ft})$ at depth $4526 \mathrm{ft}$. It is believed that the main cause of high subsurface pressure at the wells in West Qurna field is due to the influence of impermeable beds of Gotnia salt series that encountered in the Arabian gulf which extend to the south of Iraq (Fertl 1976).

The comportment of well Zubair 171 is unlike the previous wells, where the anticipated subsurface pressure gradient is normal until near depth (1939 m). Afterward, a slight abnormal pressure gradient is observed at depth range (1939-2088 m), where the predicted geopressure gradient increases from 0.42 to $0.449 \mathrm{n} \mathrm{psi} / \mathrm{ft}$. It is worthy to mention that the average normal geopressure gradient in Rumaila field (south of Iraq) which is adjacent to the selected well being investigated is equal to $(0.472 \mathrm{psi} / \mathrm{ft})$ (Almalikee and Sen 2020).

This rise in formation pressure is corresponded to Tanuma Shale formation indicating that the encountered 

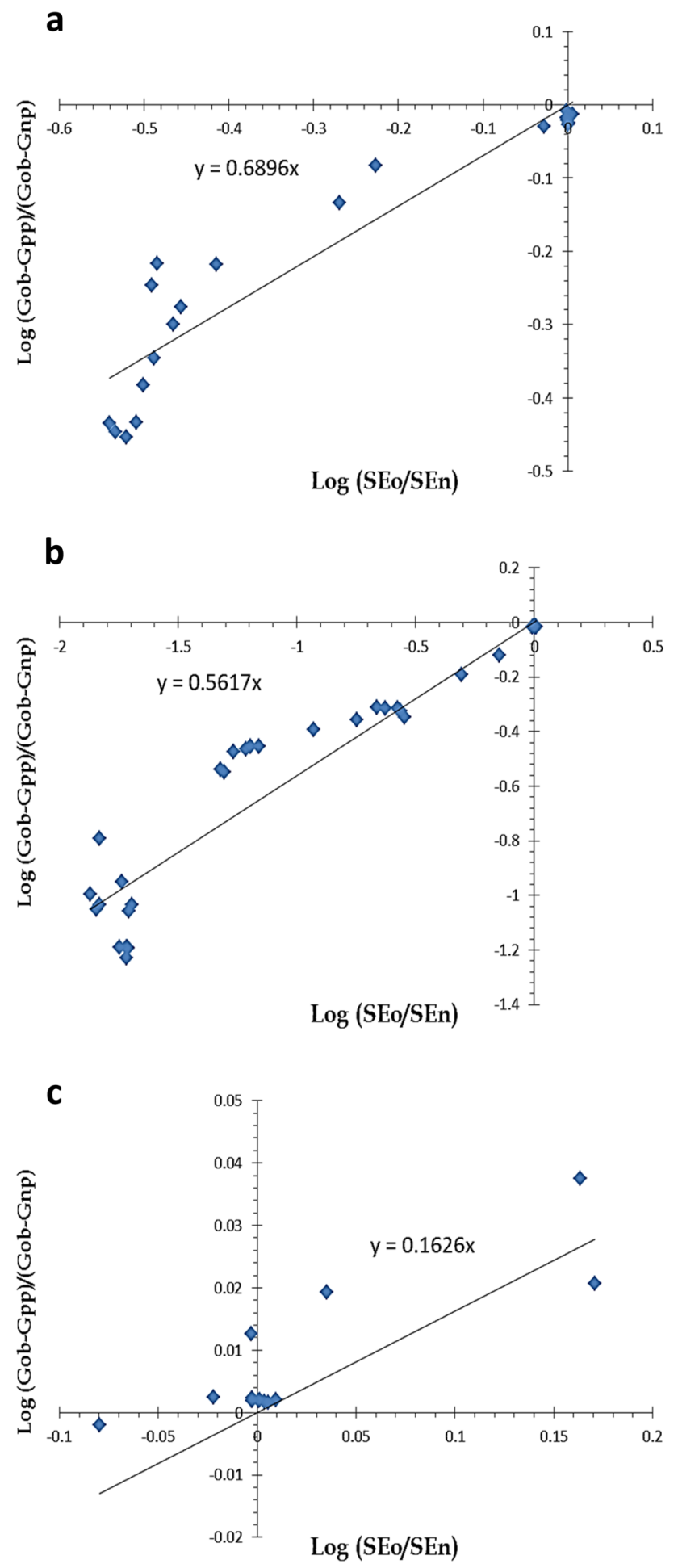

Fig. 4 Determination of the slope (m) in Eq. (8) a Missan C, b West Qurna 15, and $\mathbf{c}$ Zubair 171)

shale that have low permeability were exposed to geological under-compaction that occurred in rapid subsiding basins Then, the predicted geopressure gradient is declined until depth $(2280 \mathrm{~m})$ exhibiting a value of $(0.396 \mathrm{psi} / \mathrm{ft})$ referring to a slight subnormal pressure gradient that is corresponded to Mishrif formation. This decline in geopressure gradient is attributed to the excrescent production of hydrocarbon from this layer a long time ago resulting a considerable decrease in the geopressure pressure gradient (Almalikee and Sen 2020). After depth (2280 m), the subsurface pressure gradient started to return to its normal behavior as clearly seen in Fig. 5c.

Statistical analysis should take place to validate the predicted values of geopressure gradient with the in situ actual ones. Two statistical analysis methods were used in the present work to give robustness for the proposed approach of geopressure prediction: Statistical Mean Absolute Percentage Error (MAE) and Mean Squared Error (MSE).

Statistical Mean Absolute Percentage Error $(M A E)$ is applied for the three wells to verify the rapprochement between the anticipated and the actual geopressure gradient. For this purpose, Eq. (9) is used as mentioned previously. The obtained results of (MAE) were $(4.8865 \%)$, (3.905\%) and $(1.7242 \%)$ for wells Missan C, West Qurna 15, and Zubair 171, respectively, as demonstrated in Fig. 6. Mean Absolute Percentage Error (MAE) values for the three investigated wells were acceptable. Mean Squared Error (MSE) is also applied as shown in Eq. (10) to enhance the previous analysis where also encouraging results were obtained i.e. (0.00129), (0.00149) and (0.00009) for wells Missan C, West Qurna 15, and Zubair 171, respectively, as illustrated in Fig. 7.

According to the above statistical analysis, the present study gave a quick forecasting of the formation pressure gradient without the need for further use of well logs and other special tests such RFT and DST. However, the current study is limited for the fields that the wells are within them. Other fields in other areas require a similar study, but in general the exponent value $(m)$ in Eq. (8) is the most significant affecting parameter in the determination of the subsurface pressure.

After the validation, it is concluded that the present approach could be applied successfully to the offset wells in the specific fields. The current technique gives an instant approximation of the subsurface pressure gradient, especially when the absence of the expensive tests (RFT and (DST).

\section{Conclusions}

From the obtained results, it is concluded that overpressure zones could be detected successfully from the new proposed method as well as anticipating the subsurface pressure gradient. The value of the slope $(m)$ in Eq. (8) has a vital effect on the geopressure formula, where it varies from field to another depending on the rock type being penetrated as well as the kind of materials that

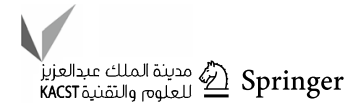


$\leadsto$ Actual pore pressure gradient (psi/ft) Cospredicted pore pressure gradient (psi/ft)

a

Subsurface Pressure gradient (psi/ft)

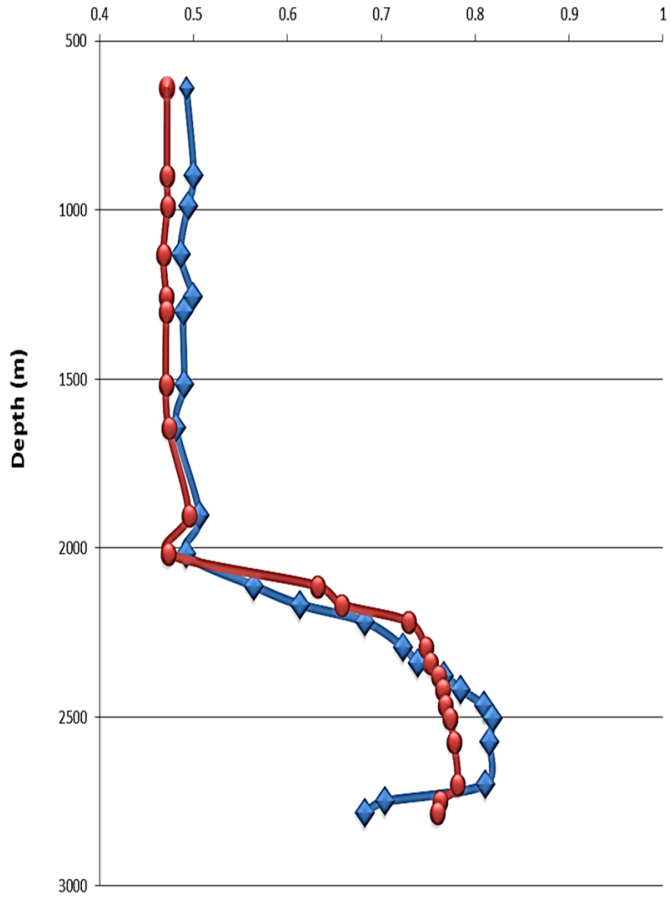

$\leadsto$ Actual pore pressure gradient (psi/ft) $\_$○Predicted pore pressure gradient psi/ft

b Subsurface Pressure gradient (psi/ft)

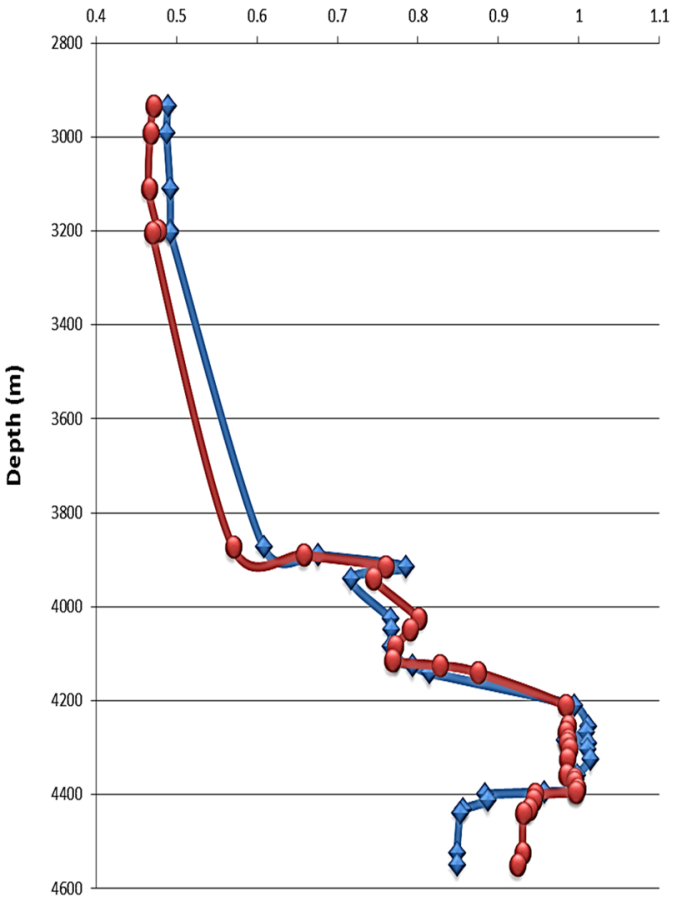

$\hookrightarrow$ Actual pore pressure gradient (psi/ft) $\quad$ co-Predicted pore pressure gradient (psi/ft)

C Subsurface Pressure gradient (psi/ft)

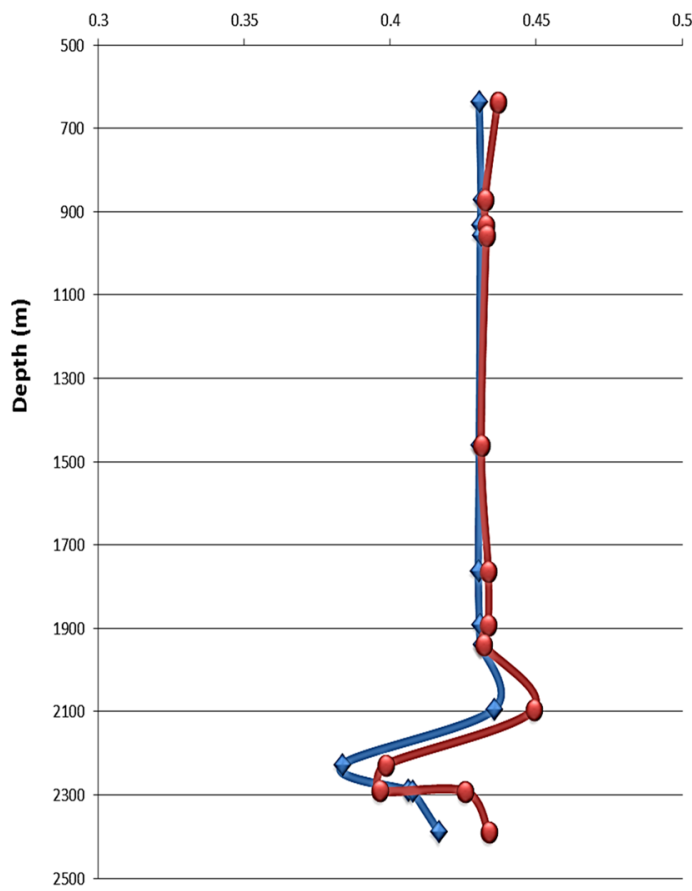


4 Fig. 5 Forecasted geopressure gradient from the proposed formula of Eq. 8 along with the in-situ actual geopressure pressure gradient vs. depth (a well Missan C, b well West Qurna 15, and c Zubair 171)

the drill bit consists of. It was concluded that the slope value $(m)$ increased in the upward direction according to the geographical location of the studied wells. The current approach found to be useful for instant prediction of geopressure gradient, especially when the costly and time consuming tests for actual pore pressure measurement especially (RFT) are unavailable. In addition, the present proposed method gives a continuous speculation of the subsurface pressure gradient with depth. The presented new technique could be implemented on other new wells, but adjacent to the investigated wells in the present research to determine the geopressure gradient, and thus all relevant considerations should be taken into account to avoid drilling problems that might be caused due to unwise prediction of geopressure. The present study could be expanded in scope to include more wells in various regions in order to establish a map of the distribution of the values of the exponent $(m)$ and the resulted formation pressure gradient.

\section{Appendix A}

Derivation of the new suggested equation of the mechanical specific energy.

From Eq. (4a):

$S E=\frac{\text { Energy rate }}{\text { Volume rate of the rock being excavated }}$

The rate of energy could be quantified from the following equation (Rabia 1985):

Enegy rate $=W \cdot r \cdot 2 \pi \cdot N$

where $N$ is the rotational speed (rpm), $W$ is the weight on bit. $(\mathrm{Kg})$, and $r$ is the bit radius: $(\mathrm{mm})$.

Rabinowicz proposed a formula for computing the volume of wear of the abraded, and the abrasive materials in three-body abrasion as happen in the drilling operation as shown in Eq. (A-2) (Rabinowicz 1977).

$V_{w}=\frac{F \cdot \tan (\theta) \cdot X}{5.3 H_{W}}\left(\frac{H_{a}}{H_{W}}\right)^{2.5} 0.8 H_{a}<H_{W}<1.25 H_{a}$

where: $H_{a}$ is the hardness of the drill bit used in the excavation, $H_{W}$ is hardness of the rock being penetrated $\left(\mathrm{N} / \mathrm{m}^{2}\right)$, $F$ is the applied load on the bit used in the penetration $(\mathrm{N})$,

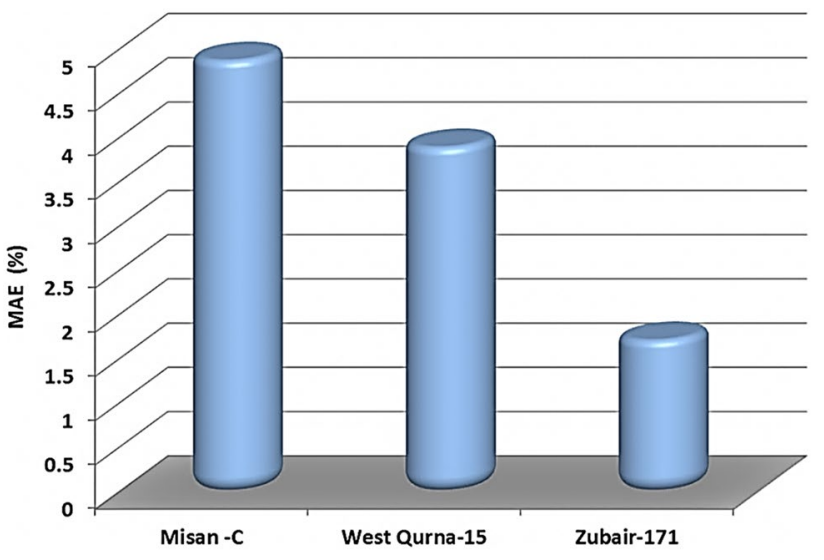

Fig. 6 Percentages of the statistical Mean Absolute Error (MAE) for the studied wells

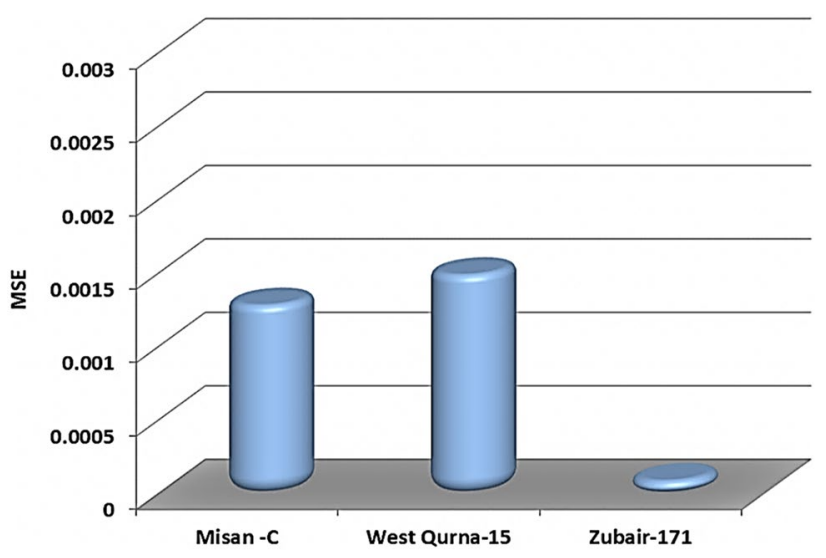

Fig. 7 Values of the statistical Mean Squared Error (MSE) for wells Missan C, West Qurna 15, and Zubair 171

$X$ is the sliding distance caused by the drill bit (m), $\theta$ is the abrasion angle, and $V_{w}$ is the volume of the material been extracted $\left(\mathrm{m}^{3}\right)$.

Equation (A-2) can be rewritten as follows:

Wear rate of the rock $\left(\frac{V_{W}}{\text { time }}\right)=\frac{W \cdot \tan (\theta) \cdot \pi N d}{5.3 H_{W}}\left(\frac{H_{a}}{H_{W}}\right)^{2.5}$

Substituting Eq. (A-1) in the numerator of Eq. (4a) and substituting eq. (A-2) in the of denominator Eq. (4a) yields the following equation:

$S E=\frac{W(K g) \cdot r(m m) \cdot 2 \pi \cdot N}{\frac{W(N) \cdot \tan (\theta) \cdot \pi N \cdot d(m)}{5.3 H_{W}}\left(\frac{H_{a}}{H_{W}}\right)^{2.5}}$

After some simplifications, Eq. (A-4) the final formula of the specific energy can be written as follows: 
$S E=\frac{K H_{W}}{\left(\frac{H_{a}}{H_{W}}\right)^{2.5}}$

where $K$ is a constant equal to $28,137.862$.

Acknowledgements The author is indebted to Dr. AbulKareem Abbas (Petroleum dept. at the Faculty of Engineering, University of Karbala) for helping to provide part of the data being used in the current study, especially for well Missan C.

Funding This research received no grant from any funding agency in the public, commercial, or not-for-profit sectors.

\section{Declarations}

Conflict of interest Rafid K. Abbas states that there is no conflict of interest.

Open Access This article is licensed under a Creative Commons Attribution 4.0 International License, which permits use, sharing, adaptation, distribution and reproduction in any medium or format, as long as you give appropriate credit to the original author(s) and the source, provide a link to the Creative Commons licence, and indicate if changes were made. The images or other third party material in this article are included in the article's Creative Commons licence, unless indicated otherwise in a credit line to the material. If material is not included in the article's Creative Commons licence and your intended use is not permitted by statutory regulation or exceeds the permitted use, you will need to obtain permission directly from the copyright holder. To view a copy of this licence, visit http://creativecommons.org/licenses/by/4.0/.

\section{References}

Abbas KR (2017) Super intendance of bit dullness using a new technique for Nasriya oil wells. J Babylon Univ Eng Sci 25:579-592

Abbas K, Jawad K, Sada Z (2020) Well logs data prediction of the nahr umr and mishrif formations in the well noor-10, southern Iraq. Iraqi Geol J 53(2A):50-67

Almahdawi F (2016) The tolerance of lime mud to effect of salt from lower faris formation missan oil fields. J Pet Res Stud 120(12):105-119

Al-Rubaiee AK (1987) Prediction of abnormal formation pressure in Misan fields. MSc. thesis submitted to the College of Engineering, Baghdad University, Petroleum Engineering Department.

Asedegbega J, Opara A, Emudianughe J et al (2021) Application of in-situ anisotropic parameters in 3D seismic velocity analysis for improved pre-drill pore pressure prediction in the onshore Niger Delta basin, Nigeria. Arab J Geosci 14:725. https://doi.org/10. 1007/s12517-021-06725-Z

Chatterjee A, Mondal S, Basu P, Patel BK (2012) Pore pressure prediction using seismic velocities for deepwater high temperaturehigh pressure well in offshore Krishna Godavari Basin, India. Paper presented at the SPE Oil and Gas India Conference and
Exhibition, Mumbai, India, March 2012. doi: https://doi.org/10. 2118/153764-MS

Eaton BA (1975) The equation for geopressure prediction from well logs. In: Fall meeting of the Society of Petroleum Engineers of AIME. Society of Petroleum Engineers

Fertl WH (1976) Abnormal formation pressures. Elsevier, Amsterdam

Fertl WH, Timko DJ (1971) Parameters for identification of overpressure formations. In: Drilling and Rock Mechanics Conference. Society of Petroleum Engineers

Gokhale BV (2010) Rotary drilling and blasting in large surface mines. CRC Press, Kent

Holm GM (1998) Distribution and origin of overpressure in the central grabin of the North Sea. Memoirs-American Ass Pet Geol, pp.123-144

Huber PJ (1964) Robust estimation of a location parameter. Ann Math stat 35(1):73-101

Almalikee HS, Sen S (2020) Present-day in situ pore pressure distribution in the tertiary and cretaceous sediments of Zubair oil field, Iraq. Asian J Earth Sci 13:1-11

IADC classification chart, Halliburton Drill Bits and Services, (2008)

Saleh TA (2018). [Topics in mining, metallurgy and materials engineering] nanotechnology in oil and gas industries II Insights into the fundamentals and principles of the oil and gas industry: the impact of nanotechnology

Markovic M, Brankovic JM, Stosovic MA et al (2021) A new method for pore pressure prediction on malfunctioning cells using artificial neural networks. Water Resour Manage 35:979-992. https:// doi.org/10.1007/s11269-021-02763-0

Mouritz AP, Hutchings IM (1991) The abrasive wear of rock drill bit materials. Soc Pet Eng

Oloruntobi O, Butt S (2019) Energy-based formation pressure prediction. J Petrol Sci Eng 173:955-964

Oloruntobi O, Adedigba S, Khan F et al (2018) Overpressure prediction using the hydro-rotary specific energy concept. J Nat Gas Sci Eng 55:243-253

Osipov AS, Bondarenko NA, Petrusha IA, Mechnik VA (2010) Drill bits with thermostable PDC inserts. Diam Tool J 70(625):31-34

Pennebaker E (1968) Detection of abnormal formation pressure from seismic-field data. American Petroleum Institute, pp 148-191

Rabia H (1985) Specific energy as a criterion for bit selection. SPE J Pet Techn 37(7):1225-1229

Rabinowicz E (1977) Abrasive wear resistance as a material test. Lubr Eng 33(7):378-381

Rehm Mcclendon, R (1971) Measurement of formation pressure from drilling data. Society of Petroleum Engineers SPE-3601

Saleh TA, Ibrahim MA (2019) Advances in functionalized Nanoparticles based drilling inhibitors for oil production. Energy Rep 5:1293-1304

Swarbrick RE, Osborne MJ, Law BE et al (1998) Abnormal pressures in hydrocarbon environments. AAPG Mem 70:13-34

Zhang J (2011) Pore pressure prediction from well logs: Methods, modifications, and new approaches. Earth Sci Rev 108(1-2):50-63. https://doi.org/10.1016/j.earscirev.2011.06.001

Publisher's Note Springer Nature remains neutral with regard to jurisdictional claims in published maps and institutional affiliations. 